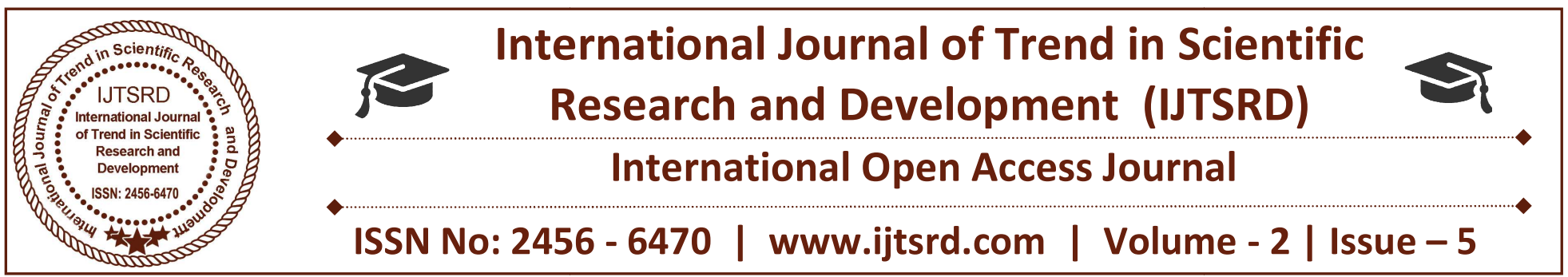

\title{
Synthesis and Characterization of Fly Ash-Zinc Oxide Nanocomposite
}

\section{Vijayalakshmi S}

Lecturer (Senior Grade) in Physics, Department of Non-Engineering, Ayya Nadar Janaki Ammal Polytechnic College, Sivakasi, Tamil Nadu, India

\section{ABSTRACT}

Fly ash, generated in thermal power plants, is recognized as an environmental pollutant. Thus, measures are required to be undertaken to dispose it in an environmentally friendly method. In this paper an attempt is made to coat zinc oxide nano-particles on the surface of fly ash by a simple and environmentally friendly facile chemical method, at room temperature. Zinc oxide may serve as effective corrosion inhibitor by providing sacrificial protection. Concentration of fly ash was varied as 5, 10 and $15(\mathrm{w} / \mathrm{w}) \%$ of zinc oxide. It was found that crystallinity increased, whereas particle size, specific gravity and oil absorption value decreased with increased concentration of fly ash in zinc oxide, which is attributed to the uniform distribution of zinc oxide on the surface of fly ash. These nanocomposites can potentially be used in commercial applications as additive for anticorrosion coatings.

Keywords: Fly ash, Zinc oxide, Pollutant, Inhibitor Specific gravity

\section{INTRODUCTION}

Nanomaterials have attracted attention because of their unique physical, chemical, and mechanical properties that differ from those of bulk solids and molecules. Nanomaterials exhibit distinct size dependent properties in the $1-100 \mathrm{~nm}$ range where quantum phenomena are involved. That is, when the particle radius approaches the asymptoticexciton Bohr radius, the influence of quantum confinement becomes apparent. The very large surface area of nanomaterials is one of the reasons for their novel properties and the high surface-to-volume ratio results in high significant effects of surface properties on their structure. Intensive research is being done for the use of nanomaterials in many applications such as energy storage, energy conversion, solar cells, pharmaceuticals, life science applications, optoelectronics, sensing and actuation nanosystems, catalysis, and composite materials.

The techniques that can be used to characterize nanomaterials include electron microscopy, scanning probe microscopies especially, atomic for cemicroscopy, x-ray diffraction, neutron diffraction, $\mathrm{x}$-ray scattering, $\mathrm{x}$-ray fluorescence spectrometry, acoustic wave technique, contact angle measurements, and various spectroscopies. The following articles describe the production and characterization of different types of nanomaterials, where the morphological, structural, and mechanical properties are determined and discussed.

The synthesis and characterization of new and novel nanomaterials with well-controlled structures, crystalline phases, shapes, sizes, and porosities are very important for breakthroughs in several technologies. The challenge for the so-called nanotechnologies is to achieve perfect control of nanoscale-related properties. This obviously requires correlating the parameters of the synthesis process with the resulting nanostructure.

Zinc oxide occurs in nature as the mineral zincite Crystalline zinc oxide exhibits piezoelectric effect and is thermo chromic, changing from white to yellow when heated [1-3].Nano zinc oxide are prepared by methods like aerosol, micro emulsion, ultrasonic, solgel method, conventional ceramic fabrication, evaporation of solutions and suspensions, evaporative decomposition of solution, solid state reaction, wet chamber synthesis and spray pyrolysis method [4, 5]. It has been known that zinc oxide is a considerable 
material for semiconductor due to its wide band gap $(3.37 \mathrm{eV})$ and its high* Corresponding author. E-mail: stmhaske@gmail.com (S. Mhaske).Excitation binding energy $(60 \mathrm{meV})$ at room temperature [6].Zinc oxide has been studied in many areas such as catalysts, electronics, optoelectronics and photochemistry in order to utilize its semiconductor characteristics $[7,8]$. Zinc oxide is also one of the most important corrosion inhibitor pigments in organic coatings [9].Since wide scale coal firing for power generation began in the 1920 s, many millions of tons of ash and related by products have been generated. The current annual production of coal ash worldwide is estimated to be around 600 million tones, with fly ash constituting about 500 million tones at $75-80 \%$ of the total ash produced. Fly ash is generally grayin color, abrasive, mostly alkaline, and refractory in nature. To improve removal efficiencies and adsorption capacities, chemical modifications of fly ash is needed [10]. Research works have been undertaken to make fly ash better usable by its surface modification, subsequently trying to make useful products from the industrial waste. Shukla et al. coated fly ash with copper by electro less coatings using Sn-Pd catalyst, in order to impart electrical conductivity to it [11]. Rohatgiet al. prepared a series of aluminum and nickel coated fly ash using pressure infiltration technique [12]. Yu utilized fly ash to more easily separate titanium dioxide photo catalyst from the treated waste water by immobilizing it on fly ash by a precipitation method [13]. Recently, Panagopoulos et al. deposited zinc-fly ash composite coatings on mild steel to improve its wear and corrosion resistance [14]. However, we propose to prepare nano-sized zinc oxide coated fly ash by a simple, convenient and environmentally friendly facile chemical method, at room temperature, to be a material of potential importance for anticorrosion in coatings; and thus providing an additional way to utilize the waste fly ash.

\section{EXPERIMENTAL}

\subsection{Materials}

Fly ash (FA) (composition: $57.13 \mathrm{wt} \% \mathrm{SiO} 2,34.24$ wt $\%$ Al2O3,2.84 wt\% $\mathrm{CaO}, 0.91 \mathrm{wt} \% \mathrm{MgO}, 2.78$ wt $\%$ Fe2O3, 0.65 wt $\%$ K2Oand 0.91 wt $\%$ TiO2; specific gravity: $2.20 \mathrm{~g} / \mathrm{cm} 3$ on Ignition(LOI): $2.90 \%$ ) was obtained from Nashik Thermal Power Plant, Nashik, India. Zinc chloride, unburned carbon determined by Loss Chemicals such as zinc acetate dihydrate, oxalic acid dihydrate, diethanolamine, and ethylene glycol was procured from M/s. S.D. Fine chemicals,

\subsection{Preparation}

$10.9 \mathrm{~g}(0.05 \mathrm{~mol})$ zinc acetate dihydrate was dissolved in distilled water at $60{ }^{\circ} \mathrm{C}$ till a transparent solution was formed. In another beaker $12.6 \mathrm{~g}(0.1 \mathrm{~mol})$ oxalic acid dihydrate was dissolved in distilled water at room temperature to get a transparent solution. This oxalic acid solution was then slowly added, under continuous stirring, into zinc acetate dehydrate solution. To this mixture $0.52 \mathrm{~g}(0.005 \mathrm{~mol})$ diethanolamine and $0.31 \mathrm{~g}(0.005 \mathrm{~mol})$ ethylene glycol was slowly added. Then predefined amount of fly ash [5 (1.17 g), $10(2.35 \mathrm{~g})$ and $15(3.52 \mathrm{~g}) \%(\mathrm{w} / \mathrm{w})$ of total quantity of zinc acetate dihydrate and oxalic acid dehydrate, nomenclatured as A1, A2 and A3, respectively] was added in order to get nanosized layer of zinc oxide (nano $\mathrm{ZnO}$ )coated fly ash. Obtained precipitate was filtered and washed2-3 times with distilled water. This precipitate was dried in oven at $80^{\circ} \mathrm{C}$ for $20 \mathrm{~h}$. The resultant white powder was calcinated at $600{ }^{\circ} \mathrm{C}$ for $2 \mathrm{~h}$. Thus, a white crystalline nano $\mathrm{ZnOcoated} \mathrm{fly} \mathrm{ash} \mathrm{powder} \mathrm{was}$ prepared.

\subsection{Characterization}

Measurements of wide angle X-ray diffraction (XRD) were 1 performed on a Rigaku Mini-Flex X-ray Diffractometer (Japan)with X-ray wavelength of $\mathrm{Cu} \mathrm{K}$ $=0.154 \mathrm{~nm}$. Fourier transform infrared (FTIR) spectroscopy was performed on a PerkinElmer Spectrum 100 Spectrophotometer (USA) using $\mathrm{KBr}$ pellet. Scanning electron microscopy (SEM) analysis was done ona JEOL, JSM-6380 LA (Japan) $15 \mathrm{kV}$ electron microscope. Specific gravity was measured by Pycnometer. Oil absorption value was measured according to the standard test method of pigments by Spatula Rub-out (ASTM D281).

\section{III.RESULTS \& DISCUSSION}

$\mathrm{X}$-ray diffract to grams obtained for the prepared nanocomposites are shown in Fig. 1. Fly ash showed its characteristic diffraction peak at around 27०, while $\mathrm{ZnO}$ showed its characteristic peaks at $31.7^{\circ}, 34.4^{\circ}$, $36.2^{\circ}, 47.5^{\circ}, 56.5^{\circ}, 62.7 \circ, 66.3^{\circ}, 67.8^{\circ}$ and $68.9^{\circ}$, respectively. All peaks are in good agreement with the standard spectrum (JCPDS nos. 36-1451 and 790205) for $\mathrm{ZnO}$. It was found that the peak intensities of $\mathrm{ZnO}$ decreased with increased concentration of fly ash. This suggests that there are kinds of interactions between $\mathrm{ZnO}$ and fly ash. Addition of fly ash had no effect on the crystallization performance of $\mathrm{ZnO}$, as there is no change in the diffraction peak positions of $\mathrm{ZnO}$. 


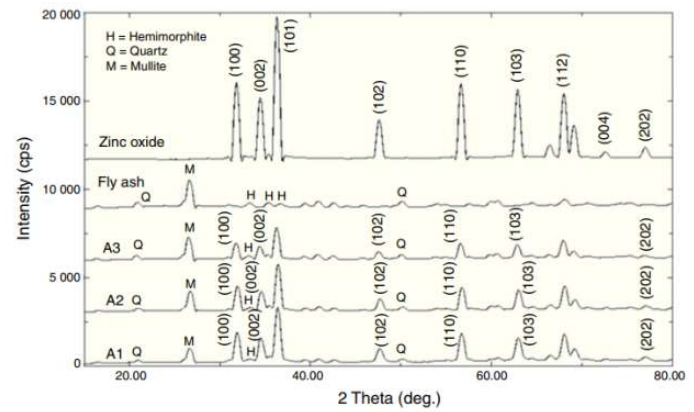

Fig. 1 - X-ray diffractograms obtained for the prepared nano $\mathrm{ZnO}$ coated fly ash nanocomposites

Nano $\mathrm{ZnO}$ was found to have diameter size ranging between 80 and $110 \mathrm{~nm}$ (Fig. 2A), while SEM micrographs for A1, A2 and A3 were shown in Fig. $2 \mathrm{~B}-\mathrm{D}$, respectively. It is clearly evident of nano $\mathrm{ZnO}$ deposition on the surface of fly ash. As the concentration of fly ash increased, more surface area of it became available for $\mathrm{ZnO}$ to deposit upon. This led to the decrease in the thickness as well as the surface roughness of the nano $\mathrm{ZnO}$ coatings on the surface of fly ash. However, surface roughness is uniform for particular concentration of fly ash. Also, the particle size of the composite decreased with increased concentration of fly ash.
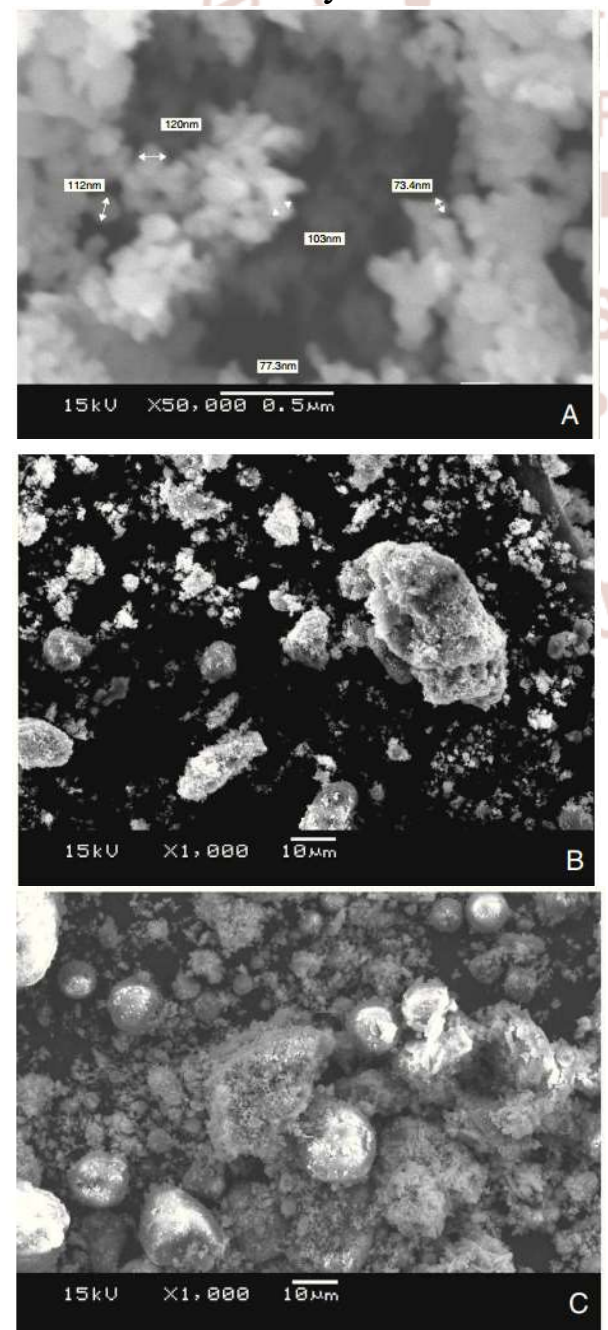

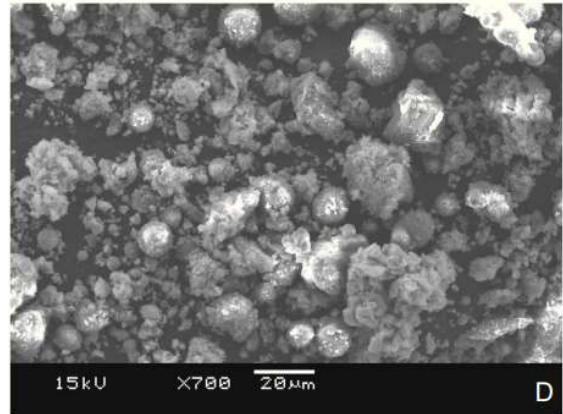

Fig. 2 - SEM micrographs obtained for $\mathrm{ZnO}$ and the prepared nano $\mathrm{ZnO}$ coated fly ash nanocomposites

FTIR spectra obtained for $\mathrm{ZnO}$, fly ash, A1, A2 and A3are shown in Fig. 3. FTIR spectra of $\mathrm{ZnO}$ show distinct $\mathrm{Zn}-$ Oabsorption band at $458.9 \mathrm{~cm}-1$, while in the FTIR of fly ash, distinct $\mathrm{Si}-\mathrm{O}-\mathrm{Si}$ peak is obtained at about $1100 \mathrm{~cm}-1$. Peak at about $3600 \mathrm{~cm}-1$ is due to the moisture adsorbed on the surface of the composite. It was found that the characteristic peak of $\mathrm{ZnO}$ decreased in intensity with increased concentration of fly ash in the composite. It can also be seen that the characteristic peaks of $\mathrm{ZnO}$ and fly ash shifted toward right with increased concentration of fly ash in the composite, which can be attributed to the interactions happening between $\mathrm{ZnO}$ and fly ash. Specific gravity of fly ash is 2.93 and that of nano $\mathrm{ZnO}$ is5.5. Specific gravity values obtained for $\mathrm{A} 1$, $\mathrm{A} 2$ and $\mathrm{A} 3$ were 5.2, 4.8 and 4.6, respectively. It was found that the specific gravity of the composite decreased with increased concentration of fly ash. This was attributed to the low density of fly ash as compared to $\mathrm{ZnO}$, leading to the decrease in the specific gravity of the composite. These specific gravity values were useful in primer formulation calculations.

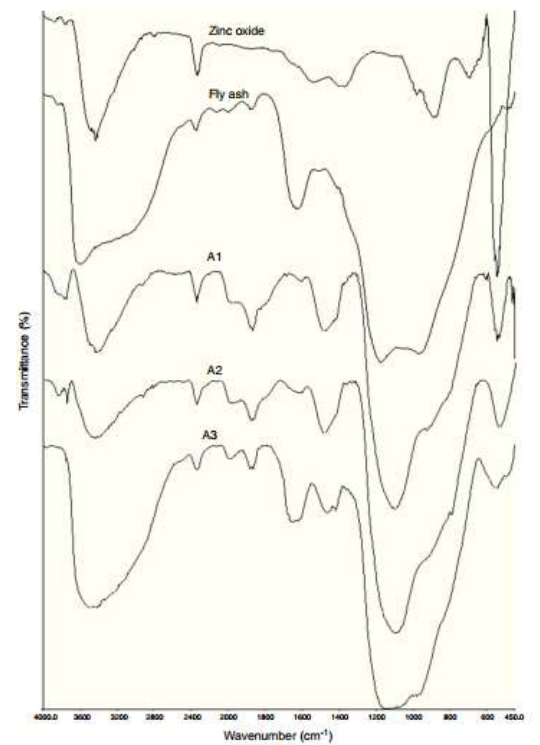

Fig. 3 - FTIR spectra obtained for ZnO, flfly ash, A1, $\mathrm{A} 2$ and $\mathrm{A} 3$ 
Oil absorption value of pigment is also very useful in formulating the paint. This value for $\mathrm{ZnO}, \mathrm{A} 1, \mathrm{~A} 2$ and A3 are 5.5, 8.5, 9.0 and 12.1 , respectively. It was determined that the oil absorption value of composite material increased with increased concentration of fly ash. There are several reasons for it. Firstly, fly ash was added maintaining the same concentration of $\mathrm{ZnO}$ every time. Thus, the addition of fly ash increases the surface area for adsorption of oil. Also, addition of fly ash increases the surface area for $\mathrm{ZnO}$ to coat on, decreasing the level aggregates and making it more uniform, again leading to the increase in surface area of $\mathrm{ZnO}$ to absorb more oil.

\section{CONCLUSION}

A novel and very simple procedure for preparing fly ash zinc oxide nanocomposites using precipitation method was utilized in the current research work. Prepared fly ash-zinc oxide nanocomposites were characterized by XRD, FTIR, SEM, specific gravity and oil absorption value. These results reveal the coating of zinc oxide on the surface of fly ash with interactions happening between them. Prepared nanocomposites can be used as pigment in antistatic coatings and anti-corrosive coatings.

\section{REFERENCES}

1. Kanade KG, Kale BB, Aiyer RC, Das BK. Effect of solvents on the synthesis of nano-size zinc oxide and its properties. Mater Res Bull 2006; 41(3):590-600.

2. Fu Z, Wang Z, Yang B, Yang Y, Yan H, Xia L. Shape-control of nano-ZnO by changing the solvent. Mater Lett2007; 61(26):4832-5.

3. $\mathrm{Li} \mathrm{Y,} \mathrm{Li} \mathrm{G,} \mathrm{Yin} \mathrm{Q.} \mathrm{Preparation} \mathrm{of} \mathrm{ZnO}$ varistors by solution nano-coating technique. Mater SciEng B 2006; 130(1):264-8.

4. Fissan H, Höllander W, Schütz W, Okuyama K. Preparation of micro-controlled particles using aerosol process. J Aerosol Sci 1991; 22: S7-10.

5. Okuyama K, Lenggoro I W, Tagami N, Tamaki S, Tohge N. Preparation of $\mathrm{ZnS}$ and $\mathrm{CdS}$ fine particles with different Document downloaded from http://www.elsevier.es, day 03/07/2018. This copy is for personal use. Any transmission of this document by any media or format is strictly prohibited. $190 \mathrm{j} \mathrm{m}$ a t e r r e s t e c h n o 1.2014 ; 3(2):186-190particle sizes by a spray-pyrolysis method. J Mater Sci1997; 32(5):1229-37.

6. Reynolds DC, Look DC, Jogai B, Hoelscher JE, Sherriff RE, Harris MT, et al. Time-resolved photoluminescence life time measurements of the sub 5 and sub 6 free excitons in ZnO. J Appl Phys 2000; 88(4):2152.

7. Pramanik P, Bhattacharya S. Deposition of molybdenumchalcogenide thin films by the chemical deposition technique and the effect of bath parameters on these thin films. Mater Res Bull 1990; 25(1):15-23.

8. Keis K, Vayssieres L, Lindquist S-E, Hagfeldt A. Nanostructured $\mathrm{ZnO}$ electrodes for photo voltaic applications. Nanostruct Mater 1999; 12(1):48790.

9. Arthur DE, Jonathan A, Ameh PO, Anya C. A review on the assessment of polymeric materials used as corrosion inhibitor of metals and alloys. Int J Ind Chem 2013; 4(1):2.

10. Joshi RC, Lothia RP. Fly ash in concrete: production, properties and uses. In: Advances in concrete technology. $1^{\text {st }}$ ed. FL: CRC Press; 1997.

11. Shukla S, Seal S, Akesson J, Oder R, Carter R, Rahman Z. Study of mechanism of electro less copper coating of fly-ash cenosphere particles. Appl Surf Sci 2001; 181(1):35-50.

12. Rohatgi P, Guo R, Iksan H, Borchelt E, Asthana R. Pressure infiltration technique for synthesis of aluminum-fly ash particulate composite. Mater SciEng A 1998; 244(1):22-30.

13. Yu Y. Preparation of nanocrystalline TiO2-coated coal fly ash and effect of iron oxides in coal fly ash on photo catalytic activity. Powder Technol 2004; 146(1):154-9.

14. Panagopoulos CN, Georgiou EP, Gavras AG. Compositezinc-fly ash coating on mild steel. Surf Coat Tech2009; 204(1):37-41.

15. Ramesh D, Vasudevan T. Synthesis and physicchemical evaluation of water-soluble epoxy ester primer coating. ProgOrg Coat 2009; 66(2):3-98. 